\title{
A case report of COVID-19 virus infection in a patient with hereditary angioedema
}

Amin S. Kanani ( $\sim$ a.kanani@ubc.ca )

University of British Columbia

\section{Case Report}

Keywords: Hereditary angioedema, COVID-19, C1 inhibitor

Posted Date: July 12th, 2020

DOI: https://doi.org/10.21203/rs.3.rs-40931/v1

License: (c) (i) This work is licensed under a Creative Commons Attribution 4.0 International License. Read Full License 


\section{Abstract}

Background: This is the first reported case of coronavirus disease of 2019 (COVID-19) in a patient with hereditary angioedema (HAE) type 1/2.

Case presentation: A female with HAE receiving $\mathrm{C} 1$ inhibitor prophylaxis had no angioedema attacks when contracting the COVID-19 virus and had a mild clinical course.

Conclusions: In this case there was no exacerbation of angioedema with the COVID-19 virus and the mild clinical course could possibly be from receiving $\mathrm{C} 1$ inhibitor prophylaxis.

\section{Background}

The SARS-CoV-2 virus has led to the global pandemic of COVID-19. ${ }^{1}$ Infection with this virus can lead to severe respiratory illness and death in some individuals. ${ }^{2} \mathrm{HAE}$ is due to a genetic mutation in the SERPING1 gene leading to a deficiency or dysfunctional $\mathrm{C} 1$ inhibitor, a protein which is involved in the complement system, contact system, coagulation, and fibrinolysis. ${ }^{3}$ Lack of $\mathrm{C} 1$ inhibitor in the contact system leads to excess bradykinin which increases vascular permeability leading to angioedema. ${ }^{4}$

\section{Case Presentation}

A 34-year-old lady with HAE contracted SARS-CoV-2 virus from a co-worker. She was diagnosed with HAE at the age of 26. She had presented with a 10 year history of recurrent abdominal pain and angioedema of the hands and feet. $\mathrm{C} 1$ inhibitor functional level was $0.26 \mathrm{U}(0.7-1.30)$ and complement $\mathrm{C} 4$ was $0.03 \mathrm{~g} / \mathrm{L}(0.10-0.50)$ at diagnosis. She has been receiving prophylactic therapy with $\mathrm{C} 1$ inhibitor (Berinert®) 1500 units IV 2 times a week for the past 6 years and her last HAE angioedema attack was 2 years ago.

In March of this year she was diagnosed with the COVID-19 virus by positive nucleic acid amplification test (NAAT) on nasopharyngeal swab. She presented with shortness of breath and non-productive cough. She also had mid-back pain and sternal pain on inspiration. She did not have a fever. She describes the shortness of breath as mild and recovered after 3-4 weeks of staying at home. She did not require emergency room visit or hospitalization. She then had a recurrence of the shortness of breath and back/sternal pain 7 weeks after the initial recovery. Nasopharyngeal swab 9 weeks after the initial positive swab was negative for the COVID-19 virus by NAAT. Computed tomography (CT) scan of the chest performed approximately 9 weeks after her initial symptoms showed mild peripheral right-sided ground-glass changes, peribronchovascular nodularity and extensive hilar/mediastinal adenopathy. Blood work from 12 weeks after initial presentation showed normal complete blood cell count with normal white blood cell count differential. She did not experience angioedema attacks during the course of her infection or the post infection period. 


\section{Discussion And Conclusions}

CT scan of the chest of this patient showed mild ground-glass changes and lymphadenopathy. Ground glass changes are well documented in SARS-CoV-2 infection and lymph node changes have also been reported. ${ }^{5}$ This patient will require further monitoring of the lymphadenopathy and investigations may be required if not resolving.

To our knowledge this is the first reported case of COVID-19 in an individual with HAE. There were no angioedema attacks during or post illness. Her mild clinical course and not requiring hospitalization could be due to her prophylactic use of $\mathrm{C} 1$ inhibitor. A clinical trial is currently underway assessing the benefit of $\mathrm{C} 1$ inhibitor in hospitalized patients with SARS-CoV-2 pneumonia by reducing uncontrolled complement activation and capillary leakage, both of which could lead to respiratory compromise. ${ }^{6}$

\section{Declarations}

Ethics approval and consent to participate

Written and informed consent was obtained from the patient.

Consent for publication

Consent for publication of this case report was obtained from the patient.

Availability of data and materials

Not applicable

Competing interests

The author has been an advisory board member and speaker for Takeda and CSL Behring, and has received research support from Takeda and BioCryst.

Funding

Self-funded

Authors' contributions

The author compiled the data and prepared the manuscript.

Acknowledgements

None

\section{References}


1. Zhu N, Zhang D, Wang W, et al. A novel coronavirus from patients with pneumonia in China, 2019. N Engl J Med 2020; 382: 727-33.

2. Berlin DA, Gulick RM, Martinez FJ. Severe Covid-19. N Engl J Med 2020; 382: 1708-1720.

3. Busse PJ, Christiansen SC. Hereditary Angioedema. N Engl J Med 2020; 382: 1136-1148.

4. Cicardi M, Zuraw BL. Angioedema Due to Bradykinin Dysregulation J Allergy Clin Immunol Pract. 2018 Jul - Aug; 6(4):1132-1141.

5. Xiong Y, Sun D, Liu Y, Fan Y, Zhao L, Li X, Zhu W. Clinical and High-Resolution CT Features of the COVID-19 Infection: Comparison of the Initial and Follow-up Changes, Invest. Radiol. 2020 June; $55(6)$.

6. ClinicalTrials.gov [Internet]. Bethesda (MD): National Library of Medicine (US). June 4 2020. Identifier NCT04414631. Conestat Alfa in the Prevention of Severe SARS-CoV-2 Infection in Hospitalized Patients With COVID-19. Available from: https://clinicaltrials.gov/ct2/show/NCT04414631. 